\title{
Kidney damage by COVID-19 and rationale for extracorporeal therapies
}

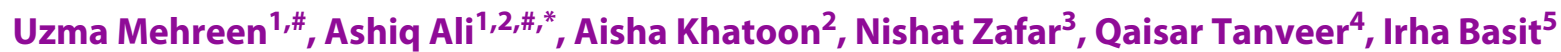

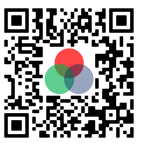

Use your smartphone to scan this QR code and download this article

"Both the authors contributed equally

${ }^{1}$ College of veterinary and animal sciences Jhang, Pakistan

${ }^{2}$ Department of Pathology, University of Agriculture Faisalabad -38000, Pakistan

${ }^{3}$ Institute of Microbiology, University of Agriculture Faisalabad -38000, Pakistan

${ }^{4}$ Institute of Pharmacy, Physiology and Pharmacology, University of Agriculture Faisalabad-38000, Pakistan

${ }^{5}$ Medicinal biochemistry lab University of Agriculture, Faisalabad Pakistan

Correspondence

Ashiq Ali

Department of Pathology, University of Agriculture Faisalabad -38000, Pakistan

Email: drashiq3485@gmail.com

History

- Received: Sep 29, 2020

- Accepted: Oct 23, 2020

- Published: Oct 31, 2020

DOI : 10.15419/bmrat.v7i10.644

\section{Check for updates}

\section{Copyright}

() Biomedpress. This is an openaccess article distributed under the terms of the Creative Commons Attribution 4.0 International license.

ABSTRACT

Without doubt, there is some involvement of the kidney in novel coronavirus disease (COVID-19), which is responsible for multiple organ dysfunctions resulting in severe complications in the human body. This newly discovered COVID-19 has incited panic globally. However, the role of kidney involvement in the novel COVID-19 disease is still unclear. In this commentary, we discuss the various pathways involved in kidney damage by COVID-19, and the rationale for extracorporeal support with various blood purification strategies in critically ill people with COVID 19.

Key words: COVID-19, Kidney, Severe disease, Organ dysfunction

\section{INTRODUCTION}

Herein, we evaluate the implicit pathways to kidney dysfunction and seek to discover the principle for extracorporeal support with various blood purification procedures in patients who are sick with COVID-19. On March 11, 2020, COVID-19 was declared as a global pandemic by the World Health Organization (WHO). According to the data last updated on 15 July 2020 by WHO, in Italy, of the patients positive for COVID-19, 47\% and $6 \%$ of those people were hospitalized or had to be admitted to the Intensive Care Unit (ICU), respectively ${ }^{1}$. In this commentary, we explore the pathogenesis and manipulation of COVID19 , as well as its associated kidney injury (AKI). Various studies have concluded that the prevalence of AKI in COVID-19 patients is low. For instance, in China, among the 1,099 people positive for COVID$19,93 \%$ of the patients were hospitalized, $91.1 \%$ of patients received a diagnosis of pneumonia, 5.3\% were admitted to the ICU, 3.4\% had acute respiratory distress syndrome (ARDS), and only $0.5 \%$ had $\mathrm{AKI}^{2}$. In these patients, there are three implicit pathways of direct kidney involvement such as systematic effect, cytokine damage, and organ crosstalk. These three phases are deeply interlinked and have major implications (Table 1).

\section{CYTOKINE IMPAIRMENT}

Cytokine release syndrome (CRS), also called a cytokine storm, was observed in many other diseases, such as hemophagocytic syndrome, sepsis, and chimeric antigen receptor (CAR) T cell therapy ${ }^{3}$.
CRS has been observed in COVID-19 since the first documented report ${ }^{4,5}$.

Patients who suffer from CRS have cardiorenal syndrome type 1 . In these patients, AKI signs include intrarenal inflammation, cardiomyopathy, increased vascular permeability, and volume depletion. The major contributing cytokine is the pro-inflammatory cytokine, IL-6. Patients with COVID-19 and ARDS have an increased plasma concentration of IL- $6{ }^{4}$. Some other factors can also contribute to cytokine generation, such as invasion mechanical ventilation, continuous kidney replacement therapy (CKRT), and extracorporeal membrane oxygenation (ECMO).

CRS in patients who have undergone CAR T-cell therapy can be treated by anti-IL-6 monoclonal antibody tocilizumab $^{3}$. It is also can be used in patients positive with COVID-19. For the patients suffering from sepsis, cytokines can be removed by extracorporeal therapies ${ }^{6}$; cytokine removal has also been favorable for those patients positive with COVID-19 ${ }^{7}$. Another benefit of cytokine removal is that it could prevent CRS-induced organ damage.

Neutro-macroporous sorbents could be used for cytokine removal. Hemoperfusion is required for more than 2 hours on 3 consecutive days. Different mechanisms are involved in the cytokine removal such as the use of neutron-macroporous sorbents for direct hemoperfusion. Plasma separation occurs from whole blood (plasma absorption on resin); CKRT entails a hollow fiber filter and high cut of (HCO) membranes with a medium cut of (MCO) membrane.

For the prevention of premature clotting, citrate or heparin should be used with blood flow $>120 \mathrm{ml} / \mathrm{min}$. 
Table 1: Potential means of kidney impairment and therapy approaches in COVID-19

\begin{tabular}{|c|c|c|}
\hline Pathways & $\begin{array}{l}\text { Means of kidney im- } \\
\text { pairment }\end{array}$ & Recommended therapy approach \\
\hline \multicolumn{3}{|l|}{ Organ crosstalk } \\
\hline Inflammation of myocardium & $\begin{array}{l}\text { Cardiorenal syndrome } \\
\text { type } 1\end{array}$ & $\begin{array}{l}\text { Left ventricular assist device, arteriovenous, ex- } \\
\text { tracorporeal membrane oxygenation }\end{array}$ \\
\hline Alveolar impairment & $\begin{array}{l}\text { Hypoxia in renal } \\
\text { medulla }\end{array}$ & Venous extracorporeal membrane oxygenation \\
\hline Intra-abdominal hypertension & $\begin{array}{l}\text { Syndrome in renal com- } \\
\text { partment }\end{array}$ & $\begin{array}{l}\text { Membrane oxygenation, extracorporeal } \mathrm{CO}_{2} \text { re- } \\
\text { moval, CKRT }\end{array}$ \\
\hline Rhabdomyolysis & Toxicity in renal tubules & $\begin{array}{l}\text { CKRT using a high } \\
\text { cut-off or medium cut-of membrane }\end{array}$ \\
\hline \multicolumn{3}{|l|}{ Systemic possessions } \\
\hline Positive fluid balance & Renal disorder & Continuous ultrafiltration and diuretics \\
\hline $\begin{array}{l}\text { Damage in the endothelium, fluid loss } \\
\text { and hypotension }\end{array}$ & $\begin{array}{l}\text { Hyperperfusion in kid- } \\
\text { ney }\end{array}$ & Fluid expansion \\
\hline Rhabdomyolysis & Tubular toxicity & $\begin{array}{l}\text { CKRT using a high } \\
\text { cut-off or MCO membrane }\end{array}$ \\
\hline Endotoxins & $\begin{array}{l}\text { Septic acute kidney in- } \\
\text { jury }\end{array}$ & Endotoxin exclusion \\
\hline \multicolumn{3}{|l|}{ Cytokine damage } \\
\hline Cytokines released disorder & Cytokine direct abrasion & $\begin{array}{l}\text { Cytokine exclusion through different strate- } \\
\text { gies: direct hemoperfusion through a neutro- } \\
\text { macroporous sorbent; }\end{array}$ \\
\hline $\begin{array}{l}\text { Elevated cytokine generation owing to } \\
\text { extracorporeal membrane oxygenation } \\
\text { (ECMO), invasive mechanical ventila- } \\
\text { tion and/or continuous kidney replace- } \\
\text { ment therapy }\end{array}$ & & $\begin{array}{l}\text { Plasma adsorption on resin after splitting from } \\
\text { whole blood; CKRT with hollow fiber filters } \\
\text { with adsorptive features; high-dose continu- } \\
\text { ous kidney replacement treatment (CKRT) with } \\
\text { medium cut-off (MCO) or high cut-off (HCO) } \\
\text { membranes }\end{array}$ \\
\hline
\end{tabular}

Cytokines absorption can also be done with CKRT filter which has specific membranes with polymethylmethacrylate, sodium methallyl sulfonate plus polyethyleneimine, or acrylonitrile which are used to absorb cytokines. These filters can be renewed every 24 hours to maximize their absorptive sites.

\section{ORGAN CROSSTALK}

According to the recent studies related to ARDS, there is a close relationship between kidney tubular-lung axis and alveolar damage ${ }^{8}$. A re-examined study conducted in 2019 showed that among 357 patients who did not have AKI before ARDS appearance and chronic kidney disease, $83 \%$ of them suffered from pneumonia, and $68 \%$ from $\mathrm{AKI}^{8}$.
In Stage-3, half of the patients were ill with kidney injury and acquired AKI. Factors which were independently related to AKI development were the severity of illness, positive fluid balance, older age, and diabetes mellitus. Increased severity of AKI was directly related to the quetelet index, history of congestive cardiac failure, diabetes mellitus, elevated peak inspiratory pressure, and consecutive organ dysfunction. Imposition prone positioning and auto positive end-expiratory pressure were not associated with kidney damage, nor did they induce nephrotoxic effects associated with $\mathrm{AKI}^{8}$.

Cytokine overproduction plays a crucial role in kidney-lung bidirectional damage. An upregulation of IL-6 in serum conduction due to the injured renal tubular epithelium has been observed. As a re- 
sult, there is pulmonary hemorrhaging and higher alveolar-capillary permeability ${ }^{9}$.

The primary involvement of proinflammatory mediators (e.g. IL-6) in injury to lung epithelium and endothelial cells still needs to be further investigated. Medullary hypoxia is another injury to tubular cells due to ARDS ${ }^{9}$. A retroactive study consisting of 201 patients positive with COVID-19 showed that $4.5 \%$ of patients developed AKI and 41.8\% developed ARDS ${ }^{4}$. Diabetes, hypertension, and older age are also factors which are related to ARDS development. However, IL-6 is related to the risk factors of patients who develop ARDS since it does not have any role in the development of ARDS.

Another study conducted in China consisted of 41 patients ${ }^{5}$ with COVID-19; of those, $27 \%$ developed ARDS, and 7\% developed AKI. Of the patients, 39\% had been admitted to the ICU, and they did not have the same IL- 6 concentration in plasma. Patients who were admitted to the ICU had a higher plasma concentration of IL-10. The higher concentration of IL10 can be a predisposing factor for immunosuppression. Specifically, there is much difference in the occurrence of AKI (4.5\%) in the patients positive with ARDS secondary to COVID-19. Differentiation to ARDS because of pneumonia was different in $68 \%$ of cases ${ }^{8}$. However, this distinction should be clarified in more detail. Heart-kidney crosstalk is assumed to play a crucial role in AKI patients positive with COVID-19. For instance, acute viral myocarditis and CRS cardiomyopathy both have a combined effect on renal hypoperfusion, renal vein congestion and hypotension, which ultimately leads to the reduction of glomerular filtration rate. It is recommended to fasten the CKRT circuit directly to the ECMO circuit. Because ECMO helps to support both lungs and heart, that is why it tends to be utilized in colligation with CKRT.

\section{SYSTEMIC EFFECT}

As fluid expansion relieves the patients from shock by making a positive fluid balance, such expansions can have harmful effects in ARDS by increasing the alveolar-capillary leakage and aggravating renal vein congestion in AKI. Thus, this leads to development of renal compartment syndrome. We contemplated that the same type of clinical physiology occurs in the patients declared with COVID-19. Unfortunately, we did not find any recent publications related to this fluid balance status. Therefore, we recommend the usage of CKRT in these patients preferably with MCO or HCO membrane. The MCO membrane has more uniformity and pore density, as compared to the $\mathrm{HCO}$ membrane, since it allows selective and effective permeability of myoglobin (17 kDa), IL-10 (18 kDa), and IL-6 (21 kDa).

Importantly, some essential characteristics like protein-binding three-dimensional configuration, electric charge, and hydrophilicity minimize the albumin loss and help to clarify the solute. If a patient has a long ICU stay and obtains an overlying infection, it can give rise to endotoxins when lipopolysaccharides explicit in the membrane of Gram-negative bacteria are metabolized by enzymes in the blood, leading to septic shock ${ }^{10}$.

A Chinese study with 1,100 patients reported in early data of COVID-19, that $64 \%$ (704 of 1,100$)$ of patients received septic shock ${ }^{2}$. We concluded that patients receiving AKR show a combined effect with other pathways of kidney damage. Patients positive with gram-negative bacterial infections and endotoxin activity assay show 0.6-0.9 \% usage of the cartridgecontaining polystyrene fibers with polymyxin-B for hemoperfusion; these play an important role in absorbing endotoxin ${ }^{11}$.

Its surface has specific sites which are used to bind endotoxin and lessen its plasma concentration. Hemoperfusion treatment is required for 2 hours for 2 succeeding days. For cytokine absorption, the use of anticoagulants can also be applied to endotoxin absorption. From our analysis, we suggest that a blood flow of about 100-120 ml/min should be used.

On the other hand, CKRT filters can also have an absorptive capacity for endotoxins. CKRT filters should be replaced daily. This daily replacement of CKRT filters is recommended without the consideration of their composition. The ICU stay with the multi-organ support is referred to as consecutive extracorporeal treatment.

\section{PREVENTION OF KIDNEY DAMAGE}

Currently, there is no specific treatment against SARSCoV-2 but further research has revealed several agents that may have potential efficacy against COVID-19. Various broad-spectrum antiviral drugs that were already approved for the treatment of other antiviral drugs are now being tested against COVID-19. These drugs may prove useful to control the kidney damage caused by COVID-19.

At the same time, anti-inflammatory drugs are used to treat this pandemic. Antiviral therapy could be applied at the early stage of this disease when anti-inflammatory therapy, like corticosteroids, could be harmful by inducing multiplication of the virus. Hence, the use of anti-inflammatory agents is most suitable when the diseases are advanced and driven 
by the hyperinflammation. However, antiviral therapy showed no results ${ }^{12}$.

\section{FUTURISTIC PERSPECTIVES}

Due to the current unavailability of a proper vaccine or recommended drug for COVID-19, the physiopathological pathways mentioned above can help to recover the critically ill. For patients with COVID-19 who are admitted to constrained treatment facilities, for particular illness like the capillary leak syndrome and vasopressor shock-like syndrome, it is noted that the level of IL-6, cytokines, and other cell cycle arrest biomarkers of AKI with high predictive values can lead to targeted and systemized standards for management of therapy.

\section{ABBREVIATIONS}

AKI: Acute kidney injury

ARDS: Acute respiratory distress syndrome

CAR: Chimeric antigen receptor

CKRT: Continuous kidney replacement therapy

CRS: Cytokines release syndrome

ECMO: Extracorporeal membrane oxygenation

HCO: High cut of

MCO: Medium cut of

\section{ACKNOWLEDGMENTS}

The author acknowledges the Department of Pathobiology College of Veterinary and Animal Sciences Jhang and Department of Pathology and Institute of Microbiology University of Agriculture Faisalabad, Pakistan.

\section{AUTHOR'S CONTRIBUTIONS}

All authors contributed equally to the idea, writing and correction of the manuscript. All authors read and approved the final version of the manuscript.

\section{FUNDING}

None.

\section{AVAILABILITY OF DATA AND MATERIALS}

Not applicable.

\section{ETHICS APPROVAL AND CONSENT TO PARTICIPATE}

Not applicable.

\section{CONSENT FOR PUBLICATION}

Not applicable.

\section{COMPETING INTERESTS}

The authors declare that they have no competing interests.

\section{REFERENCES}

1. Ministero della Salute. Covid-19. Situazione in Italia. Ministero della Salute. Salute. gov 2020; http://www.salute.gov.it/imgs/ C_17_pagineAree_5351_30_file.pdf.

2. Guan WJ, et al. Clinical characteristics of coronavirus disease 2019 in China. New England Journal of Medicine. 2020;382(18):1708-1720. PMID: 32109013. Available from: https://doi.org/10.1056/NEJMoa2002032.

3. Neelapu SS, et al. Chimeric antigen receptor T cell therapy assessment and management of toxicities. Nature Reviews Clinical Oncology. 2018;15(1):47-62. PMID: 28925994. Available from: https://doi.org/10.1038/nrclinonc.2017.148.

4. Wu C, et al. Risk factors associated with acute respiratory distress syndrome and death in patients with coronavirus disease 2019 pneumonia in Wuhan, China. JAMA Internal Medicine. 2020;180(7):934-943. PMID: 32167524. Available from: https://doi.org/10.1001/jamainternmed.2020.0994.

5. Huang $C$, et al. Clinical features of patients infected with 2019 novel coronavirus in Wuhan, China. Lancet 2020;395(10223):497-506. Available from: https://doi.org/10. 1016/S0140-6736(20)30183-5.

6. Girardot T, Schneider A, Rimmelé T. Blood purification techniques for sepsis and septic AKI. Seminars in Nephrology. 2019;39(5):505-514. PMID: 31514914. Available from: https: //doi.org/10.1016/j.semnephrol.2019.06.010.

7. Ronco C, Reis T, De Rosa S. Coronavirus epidemic, and extracorporeal therapies in intensive care. Blood Purification. 2020;49(3):255-258. PMID: 32172242. Available from: https: //doi.org/10.1159/000507039.

8. Panitchote A, et al. Factors associated with acute kidney injury in acute respiratory distress syndrome. Annals of Intensive Care. 2019;9(1):74. PMID: 31338624. Available from: https://doi.org/10.1186/s13613-019-0558-z.

9. Husain-Syed F, Slutsky AS, Ronco C. Lung-kidney crosstalk in the critically ill patient. American Journal of Respiratory and Critical Care Medicine. 2016;194(4):402-414. PMID: 27337068. Available from: https://doi.org/10.1164/rccm.201602-0420CP.

10. Ronco C, Reis T. Kidney involvement in COVID-19 and rationale for extracorporeal therapies. Nature Reviews Nephrology. 2020;16(6):308-310. PMID: 32273593. Available from: https://doi.org/10.1038/s41581-020-0284-7.

11. Klein DJ, Foster D, Walker PM, Bagshaw SM, Mekonnen H, Antonelli M. Polymyxin B hemoperfusion in endotoxemic septic shock patients without extreme endotoxemia: a post hoc analysis of the EUPHRATES trial. Intensive Care Medicine. 2018;44(12):2205-2212. PMID: 30470853. Available from: https://doi.org/10.1007/s00134-018-5463-7.

12. Jeyanathan M, Sam A, Fiona S, Mathew SM, Brian DL, Zhou S. Immunological considerations for the COVID-19 vaccine stratigies. Reviews Immunology. 2020;20(10):615-632. PMID: 32887954. Available from: https://doi.org/10.1038/s41577020-00434-6. 